\title{
Implicações do discurso parental no desvio fonológico
}

\author{
Implications of parental speech \\ for phonological disorders
}

\author{
Taís CERVI \\ Marcia KESKE-SOARES ${ }^{1}$ \\ Angela Maria Schneider DRÜGG²
}

\section{Resumo}

O desvio fonológico é uma alteração da fala sem fatores orgânicos identificáveis, que implica o uso inadequado de fonemas após os quatro anos de idade, aparecendo com maior frequência até os oito anos. Dessa forma, constitui-se objetivo deste trabalho relacionar o desvio fonológico e o discurso parental. Empregou-se uma metodologia qualitativa, a partir da análise de conteúdo. Participaram da pesquisa 15 responsáveis por crianças diagnosticadas com desvio fonológico e encaminhadas ao serviço de atendimento fonoaudiológico de uma instituição de ensino superior. Para a coleta de dados o instrumento utilizado foi uma entrevista semiestruturada. Os dados foram generalizados e compararam os participantes quanto à significação parental destinada tanto à criança quanto à patologia. Os resultados apontaram que existe uma relação entre o discurso parental e o desvio fonológico. Além disso, as funções parentais parecem determinar o quanto o funcionamento linguístico da criança é afetado por ele ou não.

Palavras-chave: Distúrbios da fala; Linguagem; Relações familiares.

\begin{abstract}
Speech disorder is an alteration of the speech that involves the inappropriate use of phonemes after 4 years of age without identifiable organic causes. Its greatest occurrence is observed between the ages of 4 and 8 years old. The objective of this study is to investigate the relationship between phonological disorders and parental speech. A qualitative content analysis was carried out. Fifteen parents or guardians of children diagnosed with phonological disorders, who were referred to the speech therapy services of a higher education institution, participated in this study. Data were collected through semi-structured interviews. The data were generalized and the parent perception of the pathology and intended support to the child were compared between the participants. The results showed that there is a relationship between parental speech and speech disorders. Moreover, parental discourse and involvement seem to determine whether the child's linguistic functioning is affected.
\end{abstract}

Keywords: Speech disorders; Language; Family relations.

\section{$\nabla \nabla \nabla \nabla$}

1 Universidade Federal de Santa Maria, Programa de Pós-Graduação em Distúrbios da Comunicação Humana. Av. Roraima, 1000, Cidade Universitária, Camobi, 97105-900, Santa Maria, RS, Brasil. Correspondência para/Correspondence to: T. CERVI. E-mail: $<$ taiscervi@hotmail.com>.

2 Universidade Regional do Noroeste do Estado do Rio Grande do Sul, Departamento de Humanidades e Educação. Ijuí, RS, Brasil. 
Pesquisas específicas consideram a relação pai-mãe-criança como outro aspecto a ser considerado, além das predisposições genéticas, na análise dos distúrbios da linguagem. Além de ser a base de toda a estruturação psíquica, essa relação é também a base da constituição linguística infantil, podendo influenciar, positivamente ou não, a aquisição e desenvolvimento da linguagem.

Para tanto, este estudo, permeado pela Psicanálise, sustenta a ideia de uma relação entre o discurso parental e o desvio fonológico. Essa relação foi identificada na significação dada à criança e ao distúrbio de fala no discurso dos responsáveis por elas.

O desvio fonológico é uma alteração da fala com uso inadequado de fonemas e sem fatores orgânicos identificáveis. Sua maior ocorrência é constatada entre quatro e oito anos de idade (Wertzner, 2004). Sabe-se que a aquisição e o desenvolvimento fonológico ocorrem de maneira gradativa, de acordo com a comunidade linguística na qual a criança está inserida (Brancalioni, Bonini, Gubiani, \& Keske-Soares, 2012; Lamprecht, 1993). É consenso que a partir dos quatro anos a maioria das crianças possui seu sistema fonológico completo (Caumo \& Ferreira, 2009). Há algumas crianças com essa idade, no entanto, que apresentam dificuldade de organizar o sistema de sons de sua língua (Pagliarin, Brancalioni, Keske-Soares, \& Souza, 2011). Essa dificuldade varia de um grau leve, envolvendo poucos sons, a um grau grave, em que há a ocorrência de múltiplos erros na fala e baixa inteligibilidade (Sices, Taylor, Freebairn, Hansen, \& Lewis, 2007), no entanto não são encontradas alterações orgânicas relacionadas (Pawlowska, Leonard, Camarata, Brown, \& Camarata, 2008). São essas as características as quais denominam o desvio fonológico.

Pouco se sabe, entretanto, sobre a etiologia dessa patologia. Alguns autores têm apontado o núcleo familiar como um dos principais fatores influentes na etiologia do desvio fonológico (Lewis et al., 2004; Mota, 2004; Pagliarin, Keske-Soares, \& Mota, 2009; Wertzner \& Papp, 2006; Wertzner, Pagan, Galea, \& Papp, 2007). A Psicanálise entende isso como o lugar simbólico, dado tanto à criança quanto ao distúrbio da fala por meio do discurso parental, onde vão se inscrevendo uma rede de significantes os quais tecem a subjetivação da criança. Com isso, vai se atribuindo à criança significados que podem fazer sintomas. Um desses sintomas pode ser a fala sintomática, ao que a Psicanálise denomina de sintoma clínico. Este surge quando a criança, por motivos subjetivos, não consegue dar conta daquilo que o Outro (mediante seus representantes - pai, mãe, educadora etc.) dela demanda e, então, passa a pôr barreiras psíquicas no real do seu corpo, preenchendo essa lacuna por meio de sintomas que aparecem no corpo, como as patologias da fala, por exemplo.

Por vezes, a sintomatologia da criança reflete a doença de outros membros da família, podendo ser a depositária da doença do pai, da mãe, do irmão ou então denunciadora de conflitos familiares. Por isso, diz-se que a criança está, desde antes do seu nascimento, inserida em um universo simbólico, carregado de significantes.

É certo que quando o indivíduo nasce é dotado de um aparelho biológico, no entanto, ele nasce, também, em um mundo simbólico, o qual tem um determinado valor, uma determinada significação e uma determinada história. É porque a criança está inserida em um mundo simbólico que o desenvolvimento da linguagem depende não somente das condições biológicas inatas de cada indivíduo, mas também de fatores ambientais presentes nos meios em que está inserida, como a família, por exemplo (Scopel, Souza, \& Lemos, 2012). Alguns autores consideram que o sujeito se constitui na medida em que suas ações vão sendo interpretadas pelo outro, por meio da internalização de papéis definidos, inicialmente, pelas pessoas que são a referência mais próxima da criança, como a família e, posteriormente, o grupo social maior do qual ela faz parte (Leite \& Monteiro, 2008).

O nascimento de uma criança ultrapassa seu nascimento biológico. Isso significa dizer que mesmo antes de ser concebida a criança já é falada no desejo e nos planos dos pais (Jerusalinsky, 2007) e esperada no registro simbólico. A preparação do enxoval, a escolha do nome, a preparação do quarto, enfim, todos os preparativos e planos fazem 
parte do discurso dos pais e da família que vão introduzindo a criança no campo simbólico (Bernardino, 2008). Assim, vai-se registrando na criança o que dela dizem os pais. Tudo isso vai configurando um sujeito determinado pelos desejos parentais que the colocam suas próprias ilusões, derivadas de suas próprias histórias. A criança é, então, um ser extremamente dependente, na medida em que necessita totalmente do cuidado do outro para poder continuar a sobreviver e subjetivar-se. São as funções materna e paterna (que podem não ser necessariamente a mãe e o pai biológicos) que vão cumprir as funções primordiais e essenciais de humanização.

A partir daí, pode-se falar em dois momentos de constituição subjetiva. No primeiro momento, o da alienação, a criança encontra-se em uma relação simbiótica com a mãe, fundamental para essa etapa, pois a mãe toma a criança como seu objeto de desejo (Kamers \& Baratto, 2004). É necessário, porém, que o desejo da mãe seja interditado para que a criança não fique na posição de responder como objeto materno. Se a criança representa o objeto o qual satisfaz completamente o desejo da mãe, não haverá lugar para que uma interrogação pelo desejo seja formulada pela criança.

É a função paterna que dará entrada ao segundo momento de constituição, a separação, a qual lembrará à mãe que a criança é um sujeito diferente dela e do qual ela não tem posse absoluta. Isso Ihe permite ver que há, no filho, desejos diferentes dos seus (Bernardino, 2008). A partir disso, introduz-se a criança no mundo do simbólico, da linguagem. É a separação que permite a função da fala (linguagem) e o aparecimento do sujeito (Campanário, 2008). Nesse sentido, há que se levar em conta que essa pré-história a qual antecede a criança, os dizeres que se fizeram em torno dela, como no caso das características a ela atribuídas, o lugar ocupado no fantasma parental, tudo será determinante na sua constituição subjetiva.

Assim, este artigo pretende analisar a possível relação entre o desvio fonológico e as significações parentais dadas a ele, buscando lançar luz sobre o discurso parental com base em recortes de elementos das entrevistas realizadas com os pais/ responsáveis. Para tanto, questiona-se as consequências da influência dos significantes parentais nessa patologia da fala.

\section{Método}

Empregou-se um delineamento de pesquisa exploratória de abordagem qualitativa, a partir da análise de conteúdo (Minayo, 2010). Optou-se por esse delineamento, uma vez que o estudo voltou-se para a elucidação e conhecimento dos complexos processos os quais constituem a subjetividade, sendo, portanto, questões muito particulares que não poderiam ser quantificadas.

\section{Participantes}

Participaram da pesquisa 15 responsáveis por crianças diagnosticadas com desvio fonológico e encaminhadas ao serviço de atendimento fonoaudiológico de uma instituição de ensino superior e que, no entanto, constavam na lista de espera do serviço. Ressalta-se que, apesar de em apenas 50\% das entrevistas ter havido a presença do casal parental, para fins de análise de dados, o casal foi considerado numericamente como sendo um responsável, o que resultou em 10 responsáveis.

Optou-se por esse número de participantes, pois a pesquisa levou em conta o estudo de Pereira e Keske-Soares (2009), que realizou o cálculo da amostra da mesma população em questão a partir do número de crianças as quais procuraram atendimento no serviço. O referido estudo concluiu que a amostra necessária para que o estudo fosse relevante seria de 15 sujeitos.

Após a seleção dos casos os responsáveis foram contatados por telefone pela pesquisadora a partir dos dados dispostos na Pasta de Registros do serviço. Antes de iniciar a entrevista os participantes foram esclarecidos acerca dos objetivos da pesquisa e dos procedimentos, além de lerem e assinarem o Termo de Consentimento Livre e Esclarecido (TCLE). 


\section{Instrumentos}

Uma entrevista inicial semiestruturada foi realizada com todos os responsáveis. O roteiro era flexível e tinha duração de, aproximadamente, uma hora, com a participação da própria pesquisadora nas salas do serviço de atendimento fonoaudiológico da Instituição de Ensino Superior. Na oportunidade, foram obtidas informações sobre a criança e a dinâmica familiar: aspectos referentes ao desejo parental em relação à criança, o lugar dado a ela na família, a significação do distúrbio de linguagem para os pais, bem como as reações diante do problema e questões relacionadas ao vínculo mãe/criança. As entrevistas foram individuais e registradas em gravador de voz digital MP3 Player para posterior transcrição e análise.

\section{Procedimentos}

As entrevistas foram analisadas qualitativamente pela pesquisadora por meio de análise temática de conteúdo, tendo o corpus das entrevistas como objeto de estudo. Dessa forma, uma vez transcritas, procurou-se identificar passagens relacionadas a categorias que abordassem questões as quais dissessem respeito ao desvio fonológico e à dinâmica familiar. Os dados obtidos foram categorizados e reagrupados conforme semelhanças. Depois, foram feitas reflexões articuladas à fundamentação teórica do estudo.

A pesquisa foi aprovada pelo Comitê de Ética em Pesquisa da Instituição de Ensino Superior em 2 de março de 2013, sob o número 12636713.6.0000.5346. Os responsáveis pelos sujeitos envolvidos assinaram o TCLE autorizando a participação e a publicação científica dos resultados, conforme Resolução n 196/96 do Conselho Nacional de Saúde (Brasil, 1996).

\section{Resultados e Discussão}

De acordo com a metodologia da análise de conteúdo, os dados foram agrupados em categorias temáticas obtidas mediante o processo de categorização das entrevistas realizadas com os respon- sáveis. Os dados de cada uma delas foram apresentados e ilustrados por excertos, discutidos e embasados teoricamente, segundo pressupostos psicanalíticos. Abaixo são apresentadas as categorias identificadas.

\section{Categoria 1: nascimento psicológico e suposição de sujeito}

Um filho nasce antes de nascer a partir do investimento psíquico de seus pais (Winnicott, 1999). Quando uma criança é concebida, já pré-existe na mãe e no pai uma organização de fantasias e expectativas ligadas à sua concepção e desenvolvimento, as quais se evidenciam nas preocupações com a gravidez, escolha do nome, preferência por sexo, expectativas sobre a fisionomia e perspectivas sociais (Cezne, Levandowski, \& Biazus, 2011)

Na intenção de identificar uma suposição de sujeito no discurso dos pais e, mais, descobrir as expectativas deles em relação à criança, algumas perguntas foram feitas. Entre elas, o que imaginavam e o que conversavam com a criança durante a gravidez. Analisando os dados, verificou-se que traços identificatórios, sexo, conversas e fantasias de como a criança seria foram pontos relevantes para a pesquisa.

Quando questionados sobre o que imaginavam sobre a criança, a resposta de $60 \%$ dos responsáveis referiu-se a expectativas relacionadas ao sexo: "Eu queria muito uma guriazinha"; "Eu achava que ia ser um guri". O restante (40\%) fez referência às características físicas do bebê: " $A$ gente ficava imaginando como ela iria ser... fisicamente... mais loirinha"; "... . Pensava que ele iria ser parecido com a mamãe ou com o papai". Já com relação ao que os pais conversavam com o bebê durante a gravidez, foram detectadas frases as quais deixavam em evidência uma suposição de sujeito: "A gente conversava como se ele já estivesse ali"; " Eu dizia assim: mexe pra mamãe saber se tu está bem!".

A suposição de sujeito é exercida pelo agente da função materna, o qual antecipa um sujeito no 
bebê tomando as reações de pouco sentido do seu filho como produções de um sujeito, atribuindo um significado a elas (Campanário, 2008). Constata-se por meio desses recortes que, em todos os casos, houve a suposição de sujeito atestando o nascimento psicológico dessas crianças, fazendo com que estejam em uma condição de sujeitos os quais se estruturam por meio da linguagem. Dessa maneira, possuem a base da estruturação psíquica e consequentemente da constituição linguística infantil.

\section{Categoria 2: adaptação do casal parental e da família ao novo membro (criança)}

Para essa categoria, selecionou-se a seguinte pergunta: "Como foi a adaptação da família e do casal ao novo membro?". Nos registros das entrevistas, observou-se que grande parte dos responsáveis $(80 \%)$ declarou ter havido mudanças na estruturação familiar. Embora fossem classificadas como sendo difíceis e desagradáveis, as mesmas fazem sentido na medida em que se referem a adaptações ao novo membro familiar, sendo que essa reestruturação significa situar a criança como um membro na família (Pereira \& Keske-Soares, 2009).

Não se pode esquecer que afetos ambivalentes marcam a relação entre os pais e o bebê, pois ao mesmo tempo em que o nascimento de um filho traz consigo expectativas também provoca uma ruptura no equilíbrio do casal (Zornig, 2010). Isso posto, fazer referência às mudanças e à reestruturação observadas durante as entrevistas é entender e situar a criança como um membro na família que, além de influenciar a estruturação familiar, também será por ela atingida. Tudo isso faz com que a criança se estruture psiquicamente de acordo com os significantes parentais nela introduzidos por meio da linguagem, das mudanças, das reorganizações etc.

As seguintes falas foram observadas nesta categoria: "A gente brigava bastante"; "Tivemos muitos problemas, até pensamos em nos separar", ou ainda, "No começo era tudo bom, depois já começaram os problemas"; "Deu tumulto, nós se separamos e fomos ficar juntos quando ela tinha um ano e pouco. Tivemos uma briga no meio da gravidez e ele disse que não era dele".

\section{Categoria 3: dificuldades de separação de vínculo}

Notou-se, durante as entrevistas, que em muitos relatos as mães referiram-se à dificuldade de quebra de vínculo e, além disso, percebeu-se que os pais, em sua maioria, são coniventes com essa situação. Por meio dessas observações, foi possível constatar que essa categoria parece estar mais diretamente relacionada com o fato estudado - a posição refratária -, pois refere-se ao posicionamento assumido por aqueles que cumprem a função materna e paterna diante da criança. Apesar da importância do vínculo inicial simbiótico entre mãe e filho, ocorrem momentos de ruptura os quais dão início ao processo de separação (Laznik, 2004; Lopes et al., 2007).

Os dados sugerem que, em geral, as mães são superprotetoras, infantilizando seus filhos, permitindo o co-leito, prolongando o uso das fraldas, do bico e da mamadeira (ou aleitamento materno por até quatro anos). Isso fez com que uma das mães verbalizasse a seguinte frase: "... . É, eu não deixo minha filha crescer, eu acho que ela não pode fazer as coisas sozinha, eu não deixo ela ser independente".

Percebe-se, como mencionado, que os pais, em muitos dos casos, são permissíveis com essas questões. Em um dos casos, a mãe contou que estava grávida de sete meses e a outra filha ainda mamava. Além disso, o pai afirmava: "Ah, deixa ela, pobrezinha, só um pouquinho". Esse fato contribui para um prolongamento do laço afetivo primordial. Esses pais pouco auxiliam no processo de crescimento de seus filhos, não favorecendo o corte necessário ao processo de mudança pelo qual a função materna tem de passar para que a criança continue seu desenvolvimento e construa uma demanda de desejo de verbalização, dado esse que corrobora o estudo de Rechia e Souza (2010).

Sabe-se que a função paterna é considerada condição para o desmame, operando como o terceiro que permite à criança afastar-se da relação dual e do desejo da mãe, privador tanto do filho quanto dela mesma (Freitas, 2005; Guerra \& Simões, 1995; Queiroz, 2005; Sales, 2005). A dificuldade 
em desmamar pode recobrir uma falha na metáfora paterna, não conseguindo operar o importante "não" no gozo entre mãe e filho, impossibilitando a substituição do seio e do leite maternos por outros objetos (Queiroz, 2005). Além disso, ao que se percebe nesta pesquisa, também causa dificuldades no desejo de adentrar no campo da linguagem e ser compreendido pelo Outro. Ao ignorar a singularidade da criança, a mãe cria obstáculos à separação e autonomia necessárias à constituiç̧ão subjetiva do filho.

Questiona-se, também, que a dificuldade enfrentada por algumas mães para realizar o desmame pode trazer consequências na relação mãe/filho, repercutindo no desenvolvimento psíquico da criança (Sampaio et al., 2010) com o risco de distúrbios infantis quanto à linguagem. Isso porque a boca se transforma em uma área de gozo.

Aceitar a intervenção paterna implica o importante jogo simbólico de substituições. É pelo processo de desmame que a mãe pode abrir mão da relação de poder e dependência da criança em relação a ela; pelo lado da criança, significa suportar a separação do corpo materno, aceitar trocas e substituições, sobretudo aceitar a convocação para o mundo da cultura (Sales, 2005) e para o mundo da linguagem, o que consiste em aceitar regras e convenções as quais fazem parte de um determinado grupo.

De acordo com Queiroz (2005), a amamentação é o tempo permitido à criança para permanecer na relação incestuosa com a mãe. Essa relação, entretanto, deve ser proibida a partir de um determinado momento e submetida a uma interdição para que a criança possa, justamente, ter acesso ao simbólico - às brincadeiras, ao campo da linguagem - e aceitar, também, outras separações subjetivantes, como o fato de dormir sozinha.

Dados desta pesquisa apontam a confirmação em relação ao exposto anteriormente, pois, em $90 \%$ dos casos, as crianças ainda dormiam no quarto dos pais ou haviam sido retiradas há pouco tempo, sendo apenas substituídas por novos irmãos. Sobre isso, uma mãe apontou: "... . É, ficou um espaço na cama, mas não deu muito tempo... logo veio o outro e ocupou o espaço. Saiu ele e veio o outro".
Constatou-se, nas respostas, que essa separação é muito mais difícil para as mães do que para as crianças: "Eu acho que é mais sofrido pra mim do que pra ele". Em muitos casos, a justificativa foi a preocupação com o sono da criança. "Eu agora to pensando em colocar ela no quarto dela, mas esses dias eu coloquei ela no quarto dela, ela dormiu tranquila, mas eu não. Toda hora eu levantava e ia ver se ela tava bem"; ou ainda, "Pra mim é difícil, eu me acordo toda noite pra olhar ela"; "Ela se destapa, daí fica doente".

\section{Categoria 4: aquisição da linguagem}

Em todos os casos, constatou-se que os responsáveis não perceberam atrasos na aquisição da linguagem, afirmando que as crianças começaram a falar entre um e dois anos de idade. Quando questionados, porém, a respeito de aspectos referentes ao desenvolvimento da linguagem, 70\% afirmou já ter se deparado com a diferença e a suposição da patologia antes da criança completar quatro anos. Em geral, observou-se que a diferença foi percebida por meio de comparações com outras crianças da mesma idade: "A gente começou a comparar ela com a priminha dela e vimos que alguma coisa estava errada"; ou "... . As coleguinhas dela já falavam certo e ela não, daí a gente viu que tinha alguma coisa".

Notou-se que, embora os responsáveis já tivessem identificado que "... algo estava errado", a maioria procurou atendimento especializado apenas quando a criança ingressou na escola. Em geral, isso ocorreu devido a questionamentos de alguma educadora sobre a dificuldade que a criança apresentava em falar corretamente.

Quando solicitado aos responsáveis que relatassem o momento a partir do qual constataram que a criança não falava corretamente, percebeu-se que o mesmo sempre esteve atrelado ao fato da criança desejar algo e não conseguir expressar isso verbalmente. Esse fato, todavia, disparava a utilização de outros recursos pelas crianças, em geral gestos apontando para o objeto desejado. Aqui cabe o relato de algumas mães as quais falaram a respeito disso: "Ele apontava o dedo pra aquilo que 
ele queria, e ganhava"; "Ele apontava e eu dava"; "Ele não dizia assim: mãe, eu quero água! Ele apontava as coisas e ganhava".

Verifica-se que a função paterna pode ser o gatilho para os sintomas da fala. É a partir de um ano e meio de idade que a criança começa a se aventurar na fala, pois é nessa época que o Nome-do-Pai começa a operar na constituição psíquica infantil. Se a criança não fala, é sinal de que não existe um desejo de investir na apropriação da língua, apesar de ter todas as condições biológicas de repetir fonologicamente pedaços de palavras (Jerusalinsky, 2004). Nos casos estudados, foi detectado que o corte da simbiose mãe-filho não ocorreu plenamente, impossibilitando o processo de mudança pelo qual a função materna deve passar para que a criança continue sua evolução da dependência absoluta para a independência (Winnicott, 1983/2007).

\section{Categoria 5: hipótese sobre a etiologia da patologia da fala}

Nessa categoria, foram observados seis tipos de hipóteses as quais apareceram no discurso dos responsáveis. Em uma das entrevistas (10\%), o responsável não apresentou hipótese alguma em relação à origem do desvio fonológico. Em outra $(10 \%)$, a mãe relatou que a etiologia da patologia estava associada à doença (leucemia) que a criança teve quando tinha um ano de idade. Uma (10\%) disse acreditar que a causa seria o incentivo do pai: "O pai dele incentiva, ele começa a falar errado com ele... fica ensinando ele falar errado". Outra $(10 \%)$, disse pensar que a causa é genética, associando a patologia com outros casos na família: "A gente já tem dois casos na família que têm problemas na fala. Então pode ser isso, pode ser genético, né!".

Em apenas uma (10\%) das entrevistas o responsável relatou que a patologia era uma "Fala infantilizada com uma dificuldade na fala". A respeito disso, acredita-se que a criança com distúrbio fonológico tenha algo relacionado a uma patologia, mas que em alguns momentos fala errado por desejo próprio, como uma forma de requerer atenção.
Na maioria dos casos (50\%), os responsáveis creem que se trata de "mimos", o que acarretaria uma fala infantilizada; isso pode ser observado na seguinte fala: "Ah, ela é uma criança mimada... daí às vezes ela começa a falar como bebezinho, faz um dengo, fica mais infantilzinha". Em outro discurso aparece: "Eu acho que às vezes ela dá uma de bebê, sabe? Quer voltar pra trás, resmunga, chora, faz manha". Dentre esses 50\%, observou-se que os responsáveis achavam "bonito" a forma errada de falar. Entre eles, destacam-se as seguintes falas: "... . A gente achava bonito quando ela falava as coisas erradas e repetia"; "É que assim, tudo que ele falava a familia achava lindo, as palavrinhas erradas dele"; "Ah, ele fala tudo, ele fala errado, troca os fonemas, mas é tão bonitinho".

Dessa forma, a hipótese mais relevante da pesquisa remete à existência de uma lacuna que é sempre preenchida. Como um espaço sempre ocupado e que leva a uma criança sempre gratificada de forma que nunca precise lidar com a falta, que não é frustrada e lesada em sua necessidade de ausência (Pereira \& Keske-Soares, 2009).

\section{Categoria 6: exercício das funções parentais em relação às regras}

Uma das questões que visava a busca do entendimento sobre como a criança se situava em relação à dinâmica familiar e às regras foi: "Quem proporciona disciplina à criança?". Em 70\% dos casos, a resposta imediata foi a mãe.

Isso foi afirmado inclusive pelos cinco pais (sujeitos que exercem a função paterna) os quais compareceram às entrevistas. Em um dos casos, ouviu-se do pai: "Ela é quem decide as regras, eu apenas apoio". Ou ainda, em outra ocasião, a mãe disse que o pai "... . Até chama a atenção, mas briga na hora errada e brinca na hora errada", e teve como resposta do próprio pai que ele "... Era mesmo muito brincalhão".

Observou-se que as mães enquadradas nesses 70\% responderam à pergunta referente às regras e limites com a queixa de que elas seriam responsáveis por isso. "Sempre sou eu quem tenho 
que colocar regras, porque lá todo mundo vive sem regras. Não tem horário, as coisas não têm lugar. $E$ quando digo não, ele não me apoia".

Em um dos casos, o pai do menino admitiu: "Eu concordo, porque assim, cada vez que saio eu volto com um presente pra ele. Eu tento suprir minha falta sendo bonzinho com ele". Ressalta-se, aqui, que a pesquisa apontou que, dentre os pais das crianças, a maioria (60\%) era de profissionais para os quais o trabalho exigia que ficassem afastados de casa por mais de uma semana, ocasionando um apego ainda maior com as mães.

A função paterna, enquanto função de mediação entre a mãe e a criança, auxilia a mãe a reconhecer o filho em sua dimensão de sujeito e alteridade (Zornig, 2010), o que faz com que a criança se direcione em relação aos seus próprios desejos, sentindo, assim, a necessidade de se comunicar. Constatou-se que a insuficiência da função paterna parece ser motivo para análise dos dados aqui apresentados. De um modo sintético, pode-se sugerir que a falta de representação mais consistente da lei desempenhada pela função paterna induziu ao prolongamento da simbiose e ocasionou uma patologia da fala nesses sujeitos.

\section{Considerações Finais}

Com este estudo, pôde-se observar que se o desvio fonológico não advém de nenhum comprometimento orgânico, então são as funções parentais que parecem determinar o quanto o funcionamento linguístico da criança é afetado ou não. Isso não significa dizer que a significação parental seja a causa do desvio fonológico e sim pensar que, a partir dos significantes atribuídos à criança, tem-se um feixe associativo, articulado a um núcleo de representações inconscientes o qual se oferece à interpretação do terapeuta. Nos casos em que o tratamento não é eficaz, entretanto, pode-se pensar que essas significações podem perfeitamente ser a causa da patologia. Por isso, o "tratamento" não pode assentar-se na busca etiológica da patologia da fala, o que leva a clínica à outra configuração, ancorada
Uma escuta permeada pela Psicanálise não implica deixar a origem e os questionamentos de lado, mas realizar uma escuta das falas sintomáticas de forma a não generalizá-las, pois seguem a natureza particular e subjetiva do sujeito, bem como as implicações dos significantes parentais. É importante salientar que o estudo sugere que todo terapeuta de criança precisa estar atento aos significantes parentais. Não se trata apenas de promover uma investigação fenomenológica, como em uma anamnese onde se busca saber como foi a gravidez, o parto, o nascimento etc., mas de ir além disso, fazendo uma escuta dos significantes os quais constituem um lugar para a criança no universo simbólico dos pais. A importância disso reside no fato de que toda a história da criança encontra-se articulada com o desejo dos pais.

\section{Colaboradores}

Todos os autores contribuíram na concepção e desenho do estudo, análise de dados e redação final.

\section{Referências}

Bernardino, L. M. F. (2008). Aspectos psíquicos do desenvolvimento infantil. In D. B. Wanderley (Org.), O cravo e a rosa: a psicanálise e a pediatria: um diálogo possivel? (pp.54-66). Salvador: Ágalma.

Brancalioni, A. R., Bonini, J. B., Gubiani, M. B., \& KeskeSoares, M. (2012). Ambientes favorecedores para a produção dos fonemas plosivos /k/ e /g/. Distúrbios da Comunicação, 24(1), 101-107.

Brasil. Conselho Nacional de Saúde. (1996). Resolução $n^{\circ} 196$, de 10 de outubro de 1996. Aprova as diretrizes e normas regulamentadoras de pesquisas envolvendo seres humanos. Diário Oficial da União, vol. 134, n 201, out.1996, Seção 1, p.20182-20186. Recuperado em abril 22, 2016, de http://conselho.saude.gov.br/ web_comissoes/conep/aquivos/resolucoes/23_out versao_final_196_ENCEP2012.pdf

Campanário, I. S. (2008). Autismo e sujeito: problemas conceituais: questões que o autismo nos coloca acerca do aparecimento do sujeito. In I. S. Campanário. Espelho, espelho meu: a psicanálise e o tratamento precoce do autismo e outras patologias graves (pp.75-111). Salvador: Ágalma.

Caumo, D. T. M., \& Ferreira, M. I. D. C. (2009). Relação entre desvios fonológicos e processamento auditivo. Revista da Sociedade Brasileira de Fonoaudiologia, 14(2), 234-240. 
Cezne, G. O. M., Levandowski, D. C., \& Biazus, C. B. (2011). "Em busca de um sonho": vivências de mulheres no contexto da infertilidade. In F. P. Jaeger, C. S. Kruel, \& A. C. Siqueira (Orgs.), Parentalidade e contemporaneidade: os desafios para a Psicologia (pp.101-122). Santa Maria: Centro Universitário Franciscano.

Freitas, L. C. C. (2005). O papel da amamentação na relação mãe-bebê no processo do desmame. In L. Sales (Org.), Pra que essa boca tão grande? Questões acerca da oralidade (pp.133-143). Salvador: Ágalma.

Guerra, A. G., \& Simões, P. (1995). Dialética da falta: da incompletude à transcendência. São Paulo: Escuta.

Jerusalinsky, A. (2004). A metáfora paterna e sua relação com a língua. In A. Vorcaro (Org.), Quem fala na língua? Sobre as psicopatologias da fala (pp.73-92). Salvador: Ágalma.

Jerusalinsky, A. (2007). Falar uma criança. In A. Jerusalinsky (Org.), Psicanálise e desenvolvimento infantil (4ª ed., pp.50-62). Porto Alegre: Artes e Ofícios.

Kamers, M., \& Baratto, G. (2004). O discurso parental e sua relação com a inscrição da criança no universo simbólico dos pais. Psicologia: Ciência e Profissão, 24(3), 40-47.

Lamprecht, R. R. (1993). Aquisição da fonologia do português na faixa dos 2:9-5:5. Letras de Hoje, 28(2), 107-17.

Laznik, M. C. (2004). A voz da sereia: o autismo e os impasses na constituição do sujeito. Salvador: Álgama.

Leite, G. A., \& Monteiro, M. I. B. (2008). A construção da identidade de sujeitos deficientes no grupo terapêutico-fonoaudiológico. Revista Brasileira de Educação Especial, 14(2), 189-200.

Lewis, B. A., Freebairn, L., Hansen, M., Taylor, H. G., lyengar, S., \& Shriberg, L. D. (2004). Family pedigrees of children with suspected childhood apraxia of speech. Journal of Communication Disorders, 13(13), 157-175.

Lopes, R. C. S., Oliveira, D. S., Vivian, A. G., Bohmgahren, L. M. C., Piccinini, C. A., \& Tudge, J. (2007). Sentimentos maternos frente ao desenvolvimento da criança de 12 meses: convivendo com as novas aquisições infantis. Psicologia: Teoria e Pesquisa, 23(1), 5-16.

Minayo, M. C. S. (2010). O desafio do conhecimento: pesquisa qualitativa em saúde $\left(12^{\mathrm{a}}\right.$ ed.). São Paulo: Hucitec.

Mota, H. B. (2004). Fonologia: intervenção. In L. P. Ferreira, D. M. Befi-Lopes, \& S. C. O. Limongi (Orgs.), Tratado de fonoaudiologia (pp.788-814). São Paulo: Rocca.

Pagliarin, K. C., Brancalioni, A. R., Keske-Soares, M., \& Souza, A. P. R. (2011). Relação entre gravidade do desvio fonológico e fatores familiares. Revista CEFAC, 13(3), 414-427.

Pagliarin, K. C., Keske-Soares, M., \& Mota, H. B. (2009). Terapia fonológica em irmãos com diferentes graus de gravidade do desvio fonológico. Revista CEFAC, $11(1), 20-24$.
Pawlowska, M., Leonard, L. B., Camarata, S. M., Brown, B., \& Camarata, M. N. (2008). Factors accounting for the ability of children with SLI to learn agreement morphemes in intervention. Journal of Child Language, 35(1), 25-53.

Pereira, A. S., \& Keske-Soares, M. (2009). Significação parental acerca do desvio fonológico. Psicologia em Estudo, 14(4), 787-795.

Queiroz, T. C. N. (2005). Amamentação e desmame. In C. M. F. Rohenkohl (Org.), A clínica com o bebê (pp.141-156). São Paulo: Casa do Psicólogo.

Rechia, I. C., \& Souza, A. P. R. (2010). Dialogia e função materna em casos de limitações práxicas verbais. Psicologia em Estudo, 15(2), 315-323.

Sales, L. M. (2005). Preocupações acerca dos efeitos psíquicos do aleitamento materno exclusivo sobre a função materna e sobre o bebê. In L. M. Sales (Org.), Pra que essa boca tão grande? Questões acerca da oralidade (pp.115-132). Salvador: Ágalma.

Sampaio, M. A., Falbo, A. R., Camarotti, M. C., Vasconcelos, M. G. L., Echeverria, A., Lima, G., ... Prado, J. V. Z. (2010). Psicodinâmica interativa mãe-criança e desmame. Psicologia: Teoria e Pesquisa, 26(4), 613-621.

Scopel, R. C., Souza, V. C., \& Lemos, S. M. A. (2012). A influência do ambiente escolar e familiar na aquisição e no desenvolvimento da linguagem: revisão de literatura. Revista CEFAC, 14(4), 732-741.

Sices, L., Taylor, H. G., Freebairn, L., Hansen, A., \& Lewis, B. (2007). Relationship between speech-sound disorders and early literacy skills in preschool-age children: Impact of comorbid language impairment. Journal of Developmental \& Behavioral Pediatrics, 28(6), 438-447.

Wertzner, A. F. (2004). Fonologia: desenvolvimento e alterações. In L. P. Ferreira, D. M. Befi-Lopes, \& S. C. O. Limongi. Tratado de fonoaudiologia (pp.772-786). São Paulo: Roca.

Wertzner, H. D., \& Papp, A. C. C. S. (2006). O aspecto familial e o transtorno fonológico. Pró-Fono: Revista de Atualização Científica, 18(2), 151-160.

Wertzner, H. F., Pagan, L. O., Galea, D. E. S., \& Papp, A. C. C. S. (2007). Características fonológicas de crianças com transtorno fonológico com e sem histórico de otite média. Revista da Sociedade Brasileira de Fonoaudiologia, 12(1), 41-47.

Winnicott, D. W. (1999). Os bebês e suas mães. São Paulo: Martins Fontes.

Winnicott, D. W. (2007). O ambiente e os processos de maturação. Porto Alegre: Artmed. (Originalmente publicado em 1983).

Zornig, S. M. A. J. (2010). Tornar-se pai, tornar-se mãe: o processo de construção da parentalidade. Tempo Psicanalítico, 42(2), 453-470.

Recebido: setembro 23, 2014

Versão final: dezembro 17, 2014

Aprovado: março 19, 2015 
